\title{
Xeroderma Pigmentosum, Complementation Group C
}

National Cancer Institute

\section{Source}

National Cancer Institute. Xeroderma Pigmentosum, Complementation Group C. NCI

Thesaurus. Code C114770.

An autosomal recessive inherited disorder caused by mutations in the XPC gene. This disease is characterized by increased sensitivity to sunlight with the development of carcinomas at an early age and is caused by a defect in nucleotide excision repair. 